\title{
Epidemiologic Profile of Vehicular Accident Patients in the Largest Hospital in the Philippines Covering Ten Years
}

\author{
Jinky Leilanie Lu, MOH, PhD, ${ }^{1}$ Teodoro J. Herbosa, MD² and Sophia Francesca D. Lu, MOS ${ }^{3}$ \\ ${ }^{1}$ National Institutes of Health, University of the Philippines Manila \\ ${ }^{2}$ Department of Emergency Medicine and Department of Surgery, College of Medicine and Philippine General Hospital, University of the Philippines Manila \\ ${ }^{3}$ School of Labor and Industrial Relations, University of the Philippines Diliman
}

\begin{abstract}
Introduction. Globally, the number of people who die from road crashes continues to rise, reaching a high of 1.35 million in 2016. Due to this continued increase in fatalities and injuries within the road transport system, especially in low- and middle-income countries, 2011 to 2020 was declared by the United Nations General Assembly in 2010 as the Decade of Action for Road Safety.

Objectives. This study looked into the epidemiology of road crashes and injuries in Metro Manila over ten years, from 2008-2017, from data gathered at the Department of Surgery of the Philippine General Hospital (PGH).

Method. A retrospective review of patients' clinical records was conducted to describe the epidemiology of road crash cases in the Trauma Division, Department of Surgery of the PGH. Clinical records of the road crash patients admitted to the division over the ten years, January 1, 2008, to December 31, 2017, were extracted from the Integrated Surgical Information System (ISIS).

Results. A total of 422 patients were admitted to the PGH Department of Surgery and recorded in the ISIS database, from 2008 to 2017, who suffered from road crashes in Metro Manila. Most of these patients (80.8\%) were male. The mean age of patients was 32.4 years. The highest number of admissions (27.5\%) and road crash deaths (6.9\%) were in 2016; the highest number was from the city of Manila (26.7\%), and most happened at nighttime (61.8\%) between 6:00 PM and 5:59 AM. Throughout the years, motorcycle (52.8\%) was the vehicle type involved. Among patients with helmet use information, $65.4 \%$ were not wearing helmets, $91.2 \%$ had a history of alcohol intake. The majority incurred multiple injuries (82.7\%), with the external region (53.8\%) as the most common. Patients who sustained injuries to their head and neck region were five times more likely to die and six times more likely to have an unchanged patient outcome than those who did not have these injuries. Patients who had a GCS of 8 and below or those who had severe brain injuries were eight times more likely to die and six times more likely to have an unchanged patient outcome.

Conclusion. This study looked into the epidemiology of road crash cases admitted to the Surgery Department of the PGH. Road crash injuries and deaths remain a growing concern among the citizens of Metro Manila. It is hoped that the results of this study will provide policymakers with an objective and data-driven perspective on road crashes.
\end{abstract}

Key Words: Metro Manila, road crash, road traffic injuries, road crash mortality

\section{INTRODUCTION}

Corresponding author: Teodoro J. Herbosa, MD

Department of Emergency Medicine and

Department of Surgery

Philippine General Hospital

University of the Philippines Manila

Taft Avenue, Ermita, Manila 1000, Philippines

Email: tjherbosa@up.edu.ph
Globally, the number of people who die from road crashes continues to rise, reaching a high of 1.35 million in 2016. In recognition of this continued increase in fatalities and injuries within the road transport system, especially in low- and middle-income countries, the years 2011 to 2020 were proclaimed by the United Nations General Assembly in 2010 as the Decade of Action for Road Safety. ${ }^{1}$ In the last 
15 years, the rate of road traffic deaths remained relatively consistent at around 18 deaths per 100,000 population, showing that the world is far from achieving Sustainable Development Goal target 3.6 - aimed at reducing the number of road traffic deaths in half by the year $2020 .^{2}$ These road crashes do not only yield human consequences but can also severely burden a country's economy, bringing about high costs including medical costs, production losses, human losses, property damage, and settlement costs. ${ }^{3}$ Moreover, road crash injuries are the only and largest cause of mortality among young people from the age bracket of 15 to 29 years old, greatly affecting the working population. Therefore, reducing these injuries can positively affect national income growth. In the case of the Philippines, reducing the road crash mortality and morbidity rates by half and sustaining it for 24 years can yield an additional income flow. ${ }^{4}$ Lowand middle-income countries lack almost everything needed to combat road crash injuries and deaths. These include the lack of leadership, lack of political priority, lack of funding, and lack of expertise. ${ }^{3}$ In the Philippines, there is no available and consistent health and non-health data for road traffic fatality at the national level from 1985 to 2013. Data observed had been present for less than five years. ${ }^{5}$ There is only the Metro Manila data on road traffic incidents maintained by the Metro Manila Development Authority (MMDA) which is the government agency in charge of transport and traffic management within the National Capital Region otherwise known as Metro Manila (MMDA, n.d.). ${ }^{6}$ Through the Metro Manila Accident Reporting and Analysis System (MMARAS), the MMDA compiles and maintains an ongoing database of road crashes happening in the National Capital Region only. ${ }^{7}$

This study explored the epidemiology of road crashes and injuries in Metro Manila over ten years, from 2008-2017, through data gathered from the Philippine General Hospital $(\mathrm{PGH})$, a state-owned tertiary hospital in Metro Manila operated by the University of the Philippines. In particular, the study aimed to explore the epidemiologic profile of road crash patients admitted at PGH's Surgery Department, such as the type of injuries and body parts injured, type of vehicles involved, type of collisions, day and time of injuries, places of injuries, and other clinical data. This aim was achieved by analyzing data obtained from the PGH - Integrated Surgical Information System (PGH-ISIS), an online electronic database maintained at the Department of Surgery.

Road safety is a significant area of concern, mainly because it is highly preventable. This research is one of many that tried to quantify the road safety problem to provide decision-makers with insights for objective policymaking.

\section{METHODS}

A retrospective review of the patients' clinical records was conducted to explore the epidemiology of road crash cases in the Trauma Division, Department of Surgery of the
PGH. Clinical records of road crash patients admitted to the division for ten years, January 1, 2007, to December 31, 2017, were extracted from the Integrated Surgical Information System (ISIS).

The PGH is a tertiary state-owned hospital operated by the University of the Philippines Manila (UP-PGH). It is designated as the National University Hospital and the national government referral hospital. It serves up to 600,000 patients every year. The PGH-ISIS houses clinical abstracts of trauma patients of the $\mathrm{PGH}$, from the emergency room to in-patient care.

The researchers requested access to the PGH-ISIS portal after securing approval from the Department of Health Single Joint Research Ethics Board (DOH-SJREB) and the UP-Manila Research Ethics Board (UPMREB). This guarantees that the researchers followed ethical practices and ensured the confidentiality of patients' data included in the study. Once PGH-ISIS approved the request for access to the portal, research assistants with health training, such as nurses, were assigned to encode data extracted from the clinical abstracts to a pre-designed template in Excel.

The PGH-ISIS is a system that digitally stores clinical abstracts of patients admitted at the PGH's Surgery Department; hence the data stored therein are exclusively PGH trauma patients. The researchers were given access to road crash patients' data in the PGH-ISIS database.

Data with the same name but with a different identifier code was treated as a separate case if the time between consult was more than three months. Also, data with the same identifier code but with a different name was considered separate if the history and diagnosis seemed independent and a new pseudo-identifier code was assigned. Expert opinion was sought during periodic meetings.

The resulting data, culled from the PGH-ISIS database, was 10-year road crash incidents from the 4979 admitted patients at the PGH Surgery Department from January 2008 to December 2017; 422 were considered in this study as these were the only patients whose Place of Incidence (POI) were within Metro Manila. Of the 422 cases, 372 were Metro Manila residents, while 46 reside outside Metro Manila but had road crash incidents in Metro Manila.

Four (4) patients who were Metro Manila residents were admitted twice and whose time between consult was more than three months. Data with the same name but with a different identifier code were treated as separate cases if the time between consult was more than three months; this represented another road crash incident encountered by the same individual. The data encoded in Excel was converted to an SPSS file for statistical analyses.

The demographic variables (age, sex, city, admission date, consult type, and patient classification,), patient history [Mechanism of Injury (MOI), Place of Injury (POI), Date of Injury (DOI), and Time of Injury (TOI), and body parts injured)] and clinical variables (Patient Outcomes, Glasgow Coma Score) were examined by descriptive statistics. 


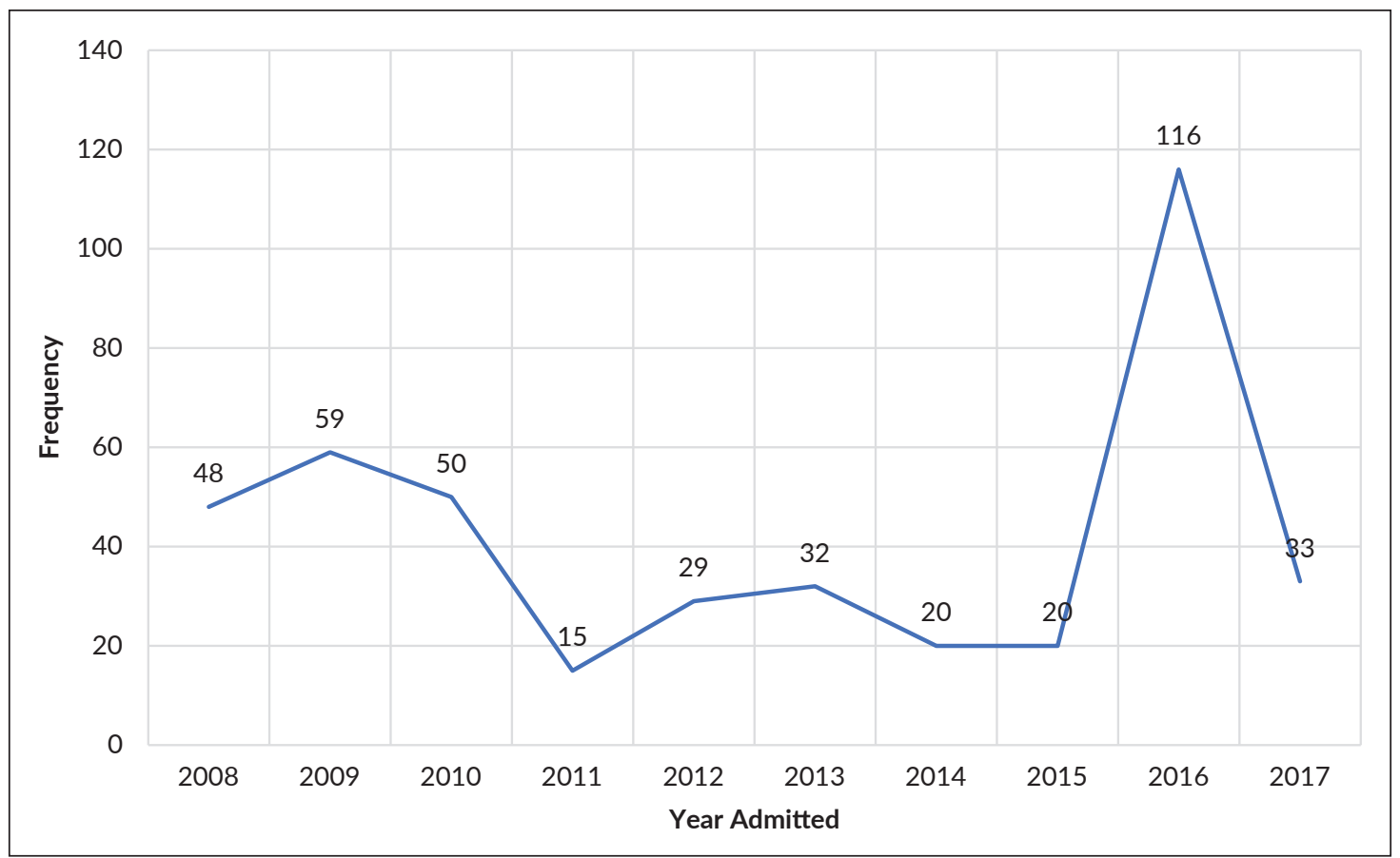

Figure 1. Distribution of patients admitted from 2008 to 2017 according to year admitted.

\section{RESULTS}

A total of 422 patients from 2008 to 2017, who suffered from road crashes in Metro Manila, were admitted to the PGH Department of Surgery and recorded in the ISIS database. Most of these patients were male (80.8\%). The mean age of the patients was 32.4 years $(\mathrm{SD}=15.7)$. Most of the road crash victims were aged 26 to 39 , comprising more than a third of the total patients admitted in Metro Manila. The majority of the patients were single (Table 1 ).

The highest number of road crash admissions was recorded in 2016, with 116 patients admitted in that year, which was more than a quarter $(27.5 \%)$ of the total patients admitted from 2008 to 2017 (Figure 1). The spike of cases in 2016 was due to increased patients that warranted admission, not necessarily due to the rise in the number of road crashes because the ISIS database only included those admitted to the PGH Department of Surgery. Among the admissions were 15 road crash deaths, 8 of which were observed in 2016, representing more than half of all the total deaths throughout the study period.

The months of July (11.2\%) and November (11.9\%) had the highest number of admissions throughout the years (Figure 3). The months with the least frequent number of reported cases were April (5.7\%) and February (6.2\%). (Table 2)

Most patients were from the cities of Manila (26.7\%), Paranaque (19.9\%), and Las Pinas (10\%). Marikina (0.2\%), San Juan (0.2\%), and Malabon (0.5\%) had the least number of recorded road crash injuries (Figure 2).
Table 1. Distribution of patients admitted according to sex, age, and civil status $(n=422)$

\begin{tabular}{lcc}
\multicolumn{1}{c}{ Sex } & Frequency & Percentage \\
Male & 341 & 80.8 \\
Female & 75 & 17.8 \\
Total & 416 & 100.0 \\
Missing & 6 & 1.4 \\
\multicolumn{1}{c}{ Age } & Frequency & Percentage \\
\hline-16 & 54 & 12.8 \\
$17-25$ & 95 & 22.5 \\
$26-39$ & 155 & 36.7 \\
$40-64$ & 97 & 23.0 \\
$65-74$ & 10 & 2.4 \\
$\geq 75$ & 6 & 1.4 \\
Missing & 5 & 1.2 \\
\multicolumn{1}{c}{ Civil Status } & Frequency & Percentage \\
Single & 232 & 55.0 \\
Married & 167 & 39.6 \\
Missing & 23 & 5.5 \\
Total & 422 & 100.0 \\
\hline
\end{tabular}

Most road crashes happened at nighttime which was from 6:00 PM to 5:59 AM (61.8\%) (Table 8): Specifically, 10:00 -10:59 PM (8.5\%), 8:00 to 8:59 PM and 11:00 to 11:59 PM (6.9\%), and 1:00 - 1:59 AM (6.2\%) (Figures 3 and 4).

Vehicle to vehicle collision (44.3\%) was the most common injury mechanism, followed by vehicle to pedestrian (27.9\%), collision with environment (2 3.3\%), vehicle to pavement (9\%), vehicle to post (3\%), and vehicle to road (1.7\%). 


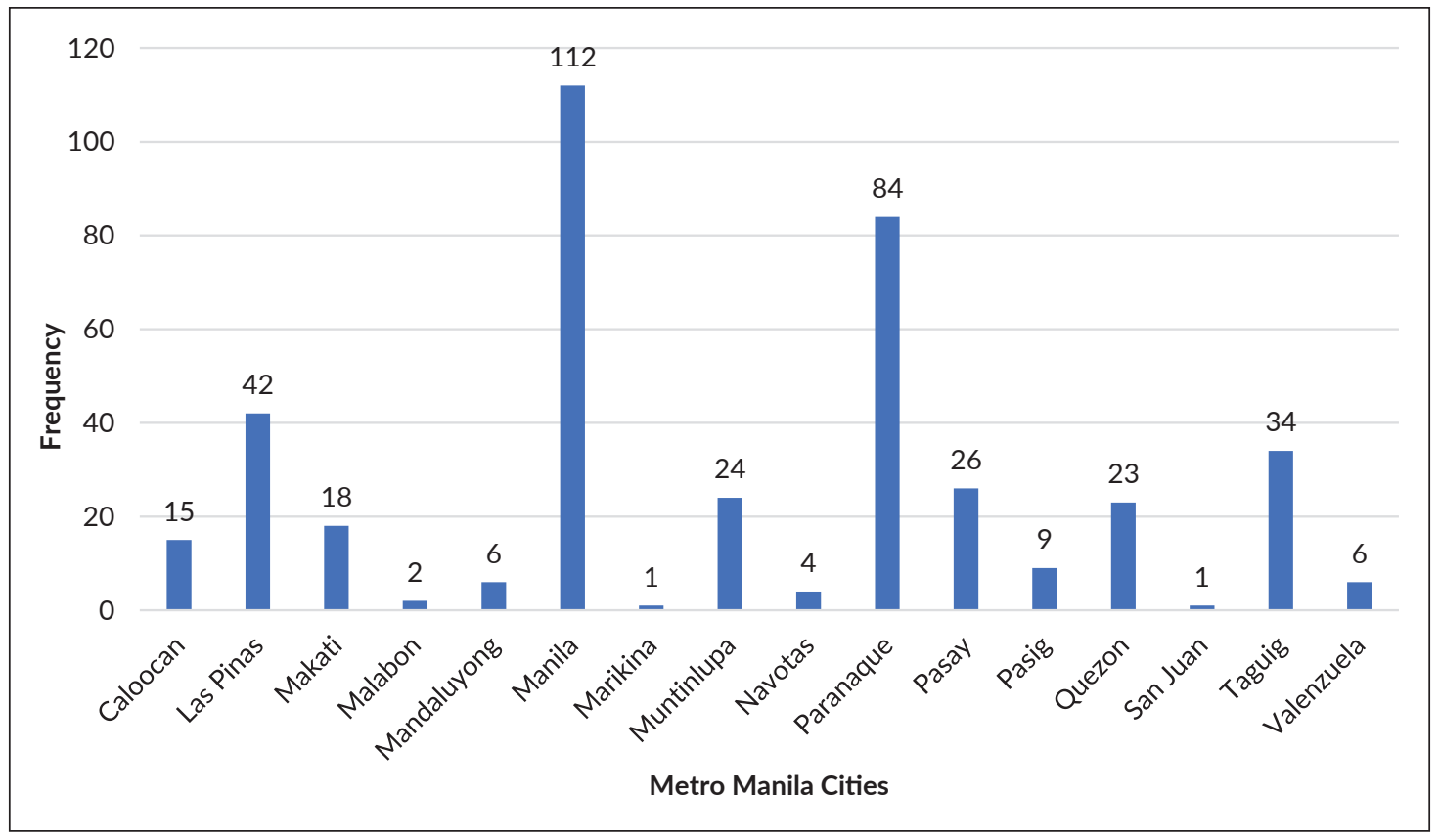

Figure 2. Distribution of road crash patients according to place of injury in various cities in Metro Manila.

Table 2. Distribution of road crash patients from 2008 to 2017 according to month

\begin{tabular}{|c|c|c|}
\hline Month Injured & Frequency & Valid Percent \\
\hline January & 32 & 7.6 \\
\hline February & 26 & 6.2 \\
\hline March & 33 & 7.9 \\
\hline April & 24 & 5.7 \\
\hline May & 26 & 6.2 \\
\hline June & 38 & 9.0 \\
\hline July & 47 & 11.2 \\
\hline August & 37 & 8.8 \\
\hline September & 29 & 6.9 \\
\hline October & 35 & 8.3 \\
\hline November & 50 & 11.9 \\
\hline December & 43 & 10.2 \\
\hline Total & 420 & 100.0 \\
\hline Missing & 2 & \\
\hline
\end{tabular}

More than half of the road crashes involved motorcycles (52.8\%), followed by bicycles, pedicabs, and motorcycles with sidecars.

Based on history, the majority (65.4\%) were not wearing helmets while driving. Almost all (91.2\%) had a history of alcohol intake.

From the list of patients involved in a motorcycle accident, 74.4\% did not have helmet use information; $88.3 \%$ had no alcohol intake information.

Most road crash patients were drivers (47.2\%), while a third were pedestrians (26.1\%) and passengers (6.6\%). (Table 3)
Table 3. Distribution of road crash patients according to the mechanism of injury, type of vehicle, and type of victim

\begin{tabular}{|c|c|c|}
\hline Mechanism of Injury & Frequency & Percentage \\
\hline Collision involving vehicles & 187 & 44.3 \\
\hline Collision involving pedestrians & 117 & 27.7 \\
\hline Damage to property & 99 & 23.5 \\
\hline Missing & 19 & 4.5 \\
\hline Type of Vehicle & Frequency & Percentage \\
\hline Motorcycle & 223 & 52.8 \\
\hline Cycle - Pedicab, Bicycle, Sidecar & 24 & 5.7 \\
\hline Motor Tricycle & 8 & 1.9 \\
\hline Car & 8 & 1.9 \\
\hline Jeepney (private and public) & 6 & 1.4 \\
\hline Van & 2 & 0.5 \\
\hline Truck & 2 & 0.5 \\
\hline Missing & 149 & 35.3 \\
\hline Type of Victim & Frequency & Percentage \\
\hline Driver & 199 & 47.2 \\
\hline Pedestrian & 110 & 26.1 \\
\hline Passenger & 28 & 6.6 \\
\hline Missing & 85 & 20.1 \\
\hline
\end{tabular}

The injuries were clustered by body region based on the Injury Severity Scoring System from the patients' final diagnosis.

More than half had injuries in their external body region (53.8\%), including lacerations, contusions, abrasions, and most burns. The most common body regions injured included the outer part, extremities, and facial area. Most patients had multiple injuries or injuries to more than one 


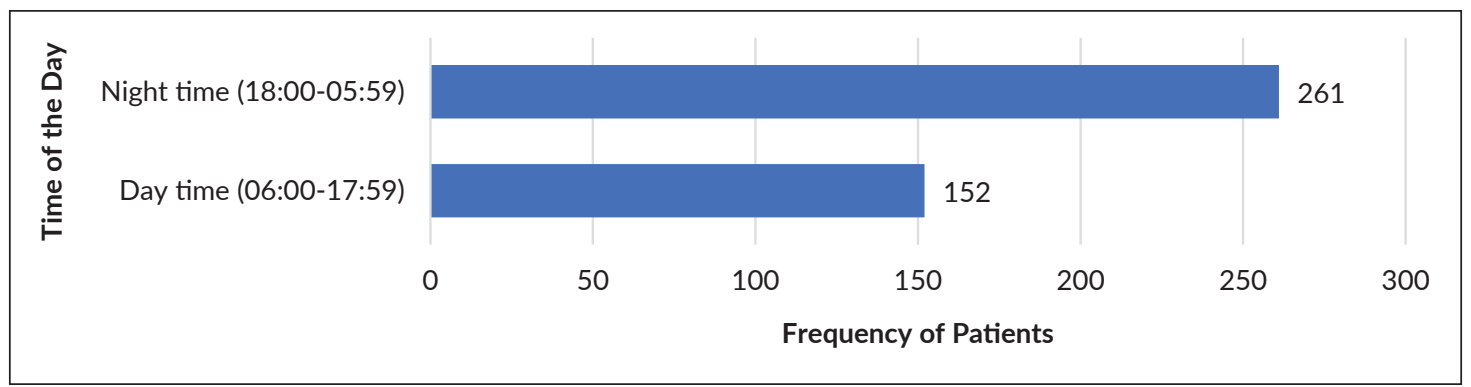

Figure 3. Distribution of road crash patients according to daytime and nighttime cases.

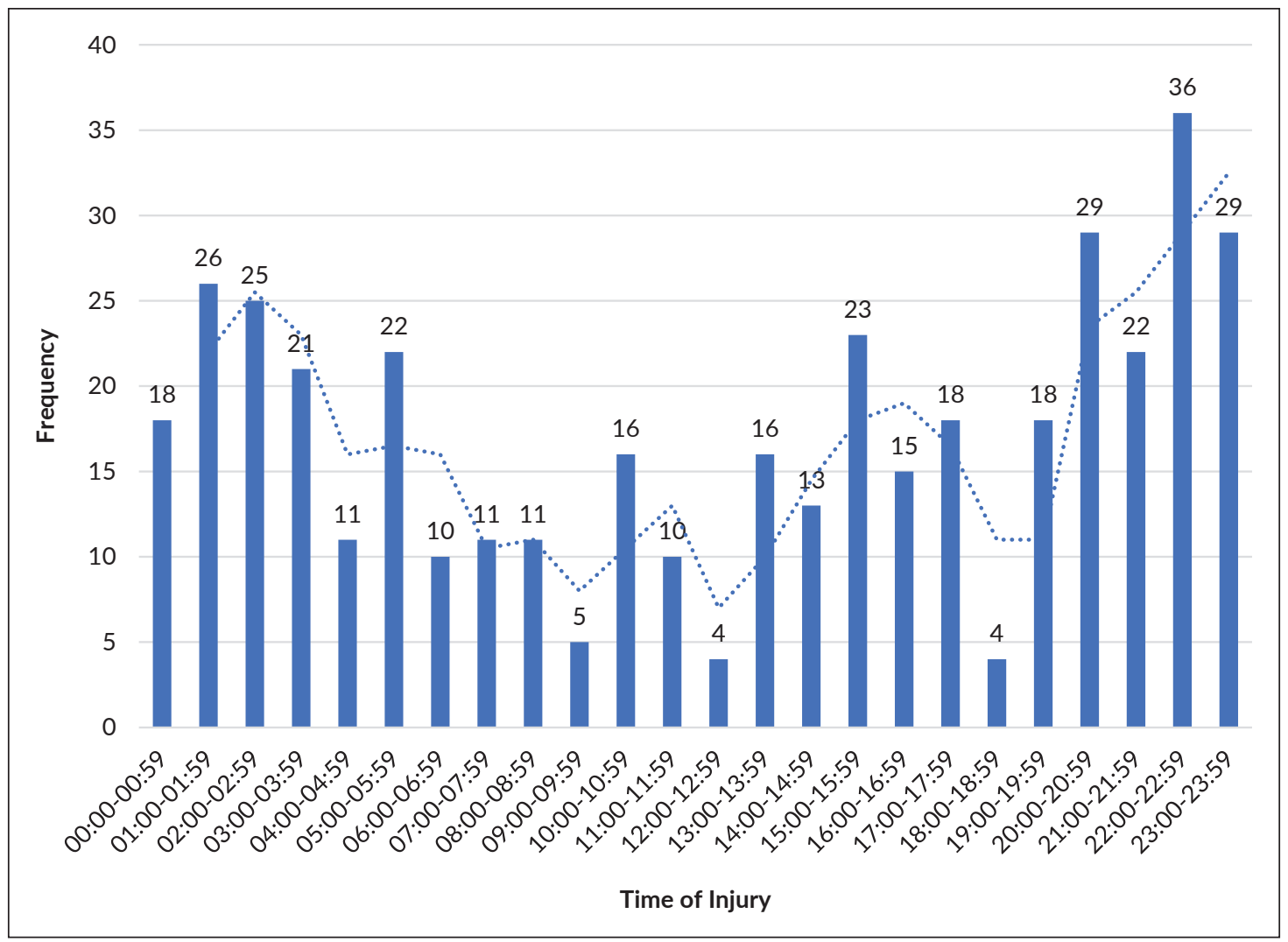

Figure 4. Distribution of road crash patients according to the time of injury.

body region. Many patients obtained injuries on two body regions, followed by a single body and three body regions. The mean number of body regions injured among all patients was 1.75 with a standard deviation of \pm 0.909 . More than one-third of the patients had injuries in their extremities (38.6\%); a quarter of the patients had injuries in their facial region $(25.1 \%)$. The majority of the road crash patients had multiple injuries (82.7\%), which meant that damages were obtained to more than one region of their body (Table 4).

Among those with final diagnoses that specified the injury by body region, almost half (42.2\%) had injuries on two body regions. This was followed by injuries to a single body region with nearly a third (30.8\%). Patients who obtained injuries to three body regions (16.8\%) made up close to a
Table 4. Distribution of road crash patients according to body regions injured, and presence of multiple injuries

\begin{tabular}{|c|c|c|c|}
\hline Body Region & Yes (\%) & No (\%) & Missing (\%) \\
\hline External & $227(53.8)$ & $191(45.3)$ & $4(0.9)$ \\
\hline Extremity & 163 (38.6) & 255 (60.4) & \\
\hline Face & $106(25.1)$ & 312 (73.9) & \\
\hline Head and Neck & 83 (19.7) & 335 (79.4) & \\
\hline Chest & 83 (19.7) & 335 (79.4) & \\
\hline Abdomen & 74 (17.5) & 344 (81.5) & \\
\hline Multiple Injuries & 349 (82.7) & 69 (16.4) & \\
\hline
\end{tabular}




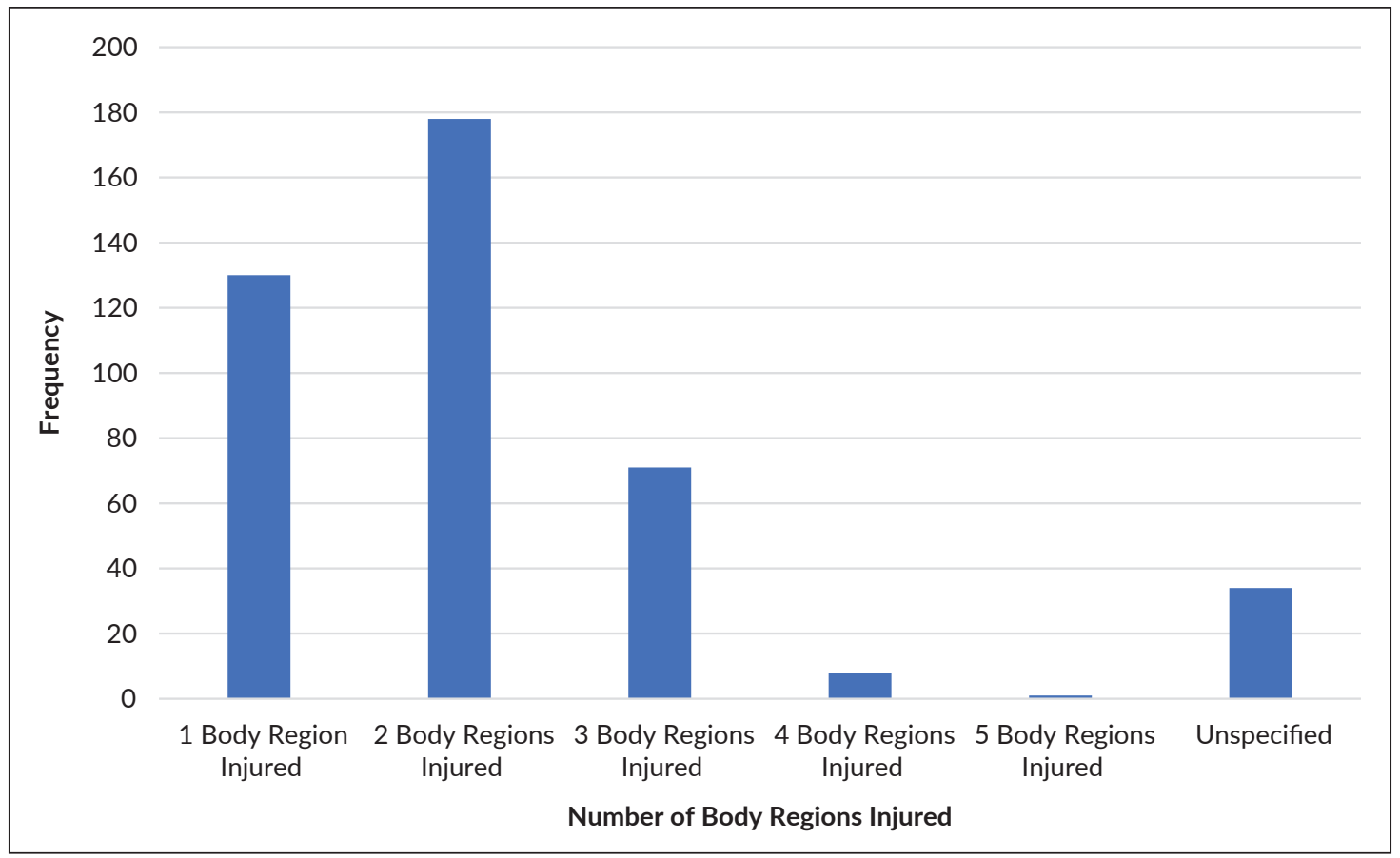

Figure 5. Distribution of road crash patients according to number of body parts injured.

fifth of all the patients. The mean number of body regions injured among all patients was $1.75(\mathrm{SD}=0.909)$. (Figure 5)

Almost all road crash patients were charity patients (97.2\%) and were urgent or emergency cases (94.5\%). A tiny percentage were pay patients $(2.8 \%)$ and had delayed or elective cases (5.5\%) (Table 5).

GCS was also looked into based on the recorded physical examination results of the patients in the database. Among

Table 5. Distribution of patients admitted in the years 2008 to 2017 according to their classification and consult availed ( $\mathrm{N}=422)$

\begin{tabular}{lcc}
\multicolumn{1}{c}{ Classification of Patient } & Frequency & Percentage \\
\hline Charity & 410 & 97.2 \\
Pay & 12 & 2.8 \\
Total & 422 & 100.0 \\
\hline \multicolumn{1}{r}{$\quad$ Type of Consult } & Frequency & Percentage \\
Urgent (Emergency) & 399 & 94.5 \\
Delayed (Elective) & 23 & 5.5 \\
Total & 422 & 100.0 \\
\hline
\end{tabular}

Table 6. Distribution of brain injury severity among patients

\begin{tabular}{lcc}
\multicolumn{1}{c}{ The severity of brain injury } & Frequency & Percent \\
based on GCS Score & 202 & 47.9 \\
No Brain Injury & 21 & 5.0 \\
Minimal Brain Injury & 20 & 4.7 \\
Moderate Brain Injury & 19 & 4.5 \\
Severe Brain Injury & 160 & 37.9 \\
Missing & 422 & 100.0 \\
\hline
\end{tabular}

the patients admitted, the majority had a GCS score of 15 (47.9\%). $4.5 \%$ of the patients admitted suffered severe brain injuries (Table 6).

Almost all patients (90.3\%) attained a recovered or improved status when they were discharged; some had unchanged status (4.7\%) from admission to discharge, and a few died (3.6\%) in the hospital (Figure 6).

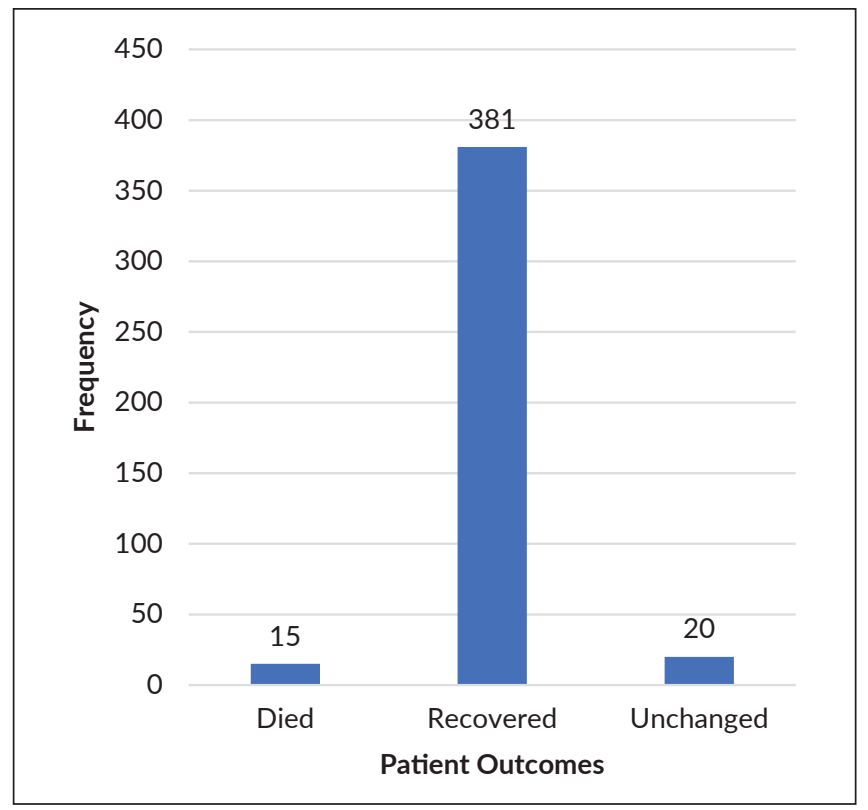

Figure 6. Distribution of road crash patients from 2008 to 2017 according to their diagnostic outcomes. 


\section{DISCUSSION}

This paper focused on the ten-year review of data of road crash patients from Metro Manila who were admitted to the region's largest trauma center.

This study was limited by the data that were only available in the PGH ISIS database. The system only included patients who were admitted to the hospital. Hence ER consults, and ER deaths, pre-hospital deaths, and death on arrival were not included in the database, including "missing data" in a patient's record.

Furthermore, this was a retrospective review of information from the ISIS database; hence, the analysis depended on the quality of the collected data.

\section{Socio-demographic Characteristics}

In low- and middle-income countries, including the Philippines, road traffic injury mortalities are concentrated on young male individuals. ${ }^{4}$ These findings are consistent with a study in Yemen where more than four-fifths of the road crash patients were males. ${ }^{8}$ Bose et al. (2011) suggested that this may influence the economic growth of the study setting. In many societies, men still tended to be household breadwinners, despite the increasing participation of females in the labor force. ${ }^{4}$

As to the age of the road crash victims, most of them belong to the younger age bracket. This was similar to the study by Useche et al. (2019) involving 20 countries in Latin America where younger age was associated with higher traffic incidents reported among cyclists, which may be related to their risk-taking behavior, as noted in the previous studies. ${ }^{9}$ This was also consistent with the findings in a Great Britain study from 2002 to 2012, where conventional crash rates were highest in the youngest age group (Regev et al., 2018). ${ }^{10}$ Specifically, daytime crashes were highest among drivers aged 21 to 29 years old, while nighttime crashes were highest among the 21 -to-29 age group. ${ }^{10}$

\section{Date of Injury}

From 2008 to 2017, no consistent trend can be seen with the number of road crash patients injured in Metro Manila and admitted to PGH. This may be because of numerous hospitals in Metro Manila that cater to road crash injured patients. This finding was similar to the annual report by the Metro Manila Accident Recording and Analysis System (MMARAS), an ongoing database of road crashes compiled and maintained by the Road Safety Unit (RSU) of the MMDA-Traffic Discipline Office-Traffic Engineering Center (MMDA-TDO-TEC), with the cooperation and assistance of the Traffic Enforcement Group under the National Capital Regional Police Office (TEG-NCRPO), Philippine National Police (PNP) (MMDA, 2012-2016). ${ }^{11-15}$ Based on the annual reports from 2007 to 2017, there was no consistent trend in the number of people injured due to road crash incidents from 2012 to 2017 in Metro Manila. ${ }^{7}$
However, the number of road crash cases every year increased, except between the years 2010 and 2011 (Appendix B). ${ }^{7}$ This may be related to the consistently increasing number of registered vehicles from 2010 to 2018, leading to congestion of roads in Metro Manila, thereby increasing the risk of road crashes. ${ }^{7,16}$ The highest number of road crash admissions from Metro Manila was seen in 2016.

Similarly, no consistent trend was seen with the deaths throughout the study period, but in 2016, the highest road crash deaths were recorded in PGH. Compared to this, the number of people killed on the road because of road crash incidents in Metro Manila consistently rose from 2012 to 2017, except in 2016 (Appendix A). ${ }^{7}$

Worldwide, road traffic injuries are ranked as the $8^{\text {th }}$ leading cause of death across all ages, with the continuous rise in road traffic deaths every year. Despite this trend, Karlaftis (1998) noted that the death rate in recent years has stabilized and declined relative to the number of motor vehicles (cited by WHO, 2018, p.4). ${ }^{2}$ In Metro Manila, road crash deaths per 100,000 registered from 2012 to 2017 increased, with August and November having the highest frequency in road crash cases. ${ }^{7}$

\section{Place of Injury}

The cities of Manila, where PGH is located, Paranaque and Las Pinas, had the highest road crash cases in PGH during the study period. In the MMARAS reports, the city of Manila ranked only third with the highest road crash cases from 2012 to 2017; Makati City ranked second, and Quezon City had the highest number of cases (Appendix F). ${ }^{7}$

These cities are among the largest cities in the region and comprise the Central Business Districts with high social and economic activities. These are also where five of the seven major thoroughfares are found, including EDSA, Commonwealth Ave., Quezon Ave., Roxas Blvd., and Radial Road 10 (MMDA, 2016). ${ }^{15}$

\section{Time of Injury}

The lighting condition of the roads is a significant parameter to road crash frequencies and severity. ${ }^{17}$ Most of the Metro Manila patients admitted to PGH were injured in road crashes during nighttime, from 6:00 PM to 5:59 AM.

Nighttime, or more specifically, the dusk and dark timings, as Ali and Sheeraz (2014) termed, is critical when road crashes occur due to the involvement of factors such as insufficient illumination and glare recovery action. ${ }^{18}$ It is during this time, artificial illumination of signs is required, either by permanent fixtures or reliance on the vehicle's headlights. ${ }^{18}$ It is also during this time when drivers are usually less cautious because of lower traffic volumes and relatively sufficient sight distance, which may also explain why drivers tend to exceed the speed limit. ${ }^{17-19}$ However, other studies suggested otherwise - drivers tend to drive at a higher speed during the daytime, which maybe because of the limited visibility in the dark..$^{17,20,21}$ 
According to the Metropolitan Manila Development Authority (MMDA), the majority of road crash incidents from 2012 to 2017 in Metro Manila as a whole happened during the daytime, from 6:00 AM to 5:59 $\mathrm{PM}^{7}$ The majority of the MMDA data was "damage to property" crashes.

Metro Manila roads are highly congested during the day. Traffic is less congested during the night, which opens for more opportunities for road users to over speed, leading to road crash incidents involving human victims and damage to property.

\section{Mechanism of Injury}

The mechanism of injury with the highest cases was a vehicle-to-vehicle collision, followed by a vehicle to the pedestrian collision. The collision with the environment causing damage to property had the lowest cases.

An alarming finding of the study was that more than half of the Metro Manila Road crash patients admitted to PGH during the study period involved motorcycles. In the reports released by the MMDA, the vehicle group with the most significant number of road crash cases from 2012 to 2017 was the group of cars followed by motorcycles. ${ }^{7}$ Out of those involved in motorcycles with information on helmet use, the majority were not wearing helmets.

In a retrospective review, clinical records of motorcyclerelated trauma of patients from 2004 to 2006 yielded the same findings wherein most patients with data on alcohol intake reported that they consumed alcohol before the crash. Only a small percentage of those with information on helmet use was wearing a helmet during the crash. ${ }^{22}$

According to the WHO Global Status Report (2018), two- and three-wheelers on the world's roads increased by 10\% from 2013 to 2016. ${ }^{2}$ And among these users, head injuries ranked as the leading cause of major trauma cases. With this, countries must have legislation on helmet use by all passengers, including children. This must be supported with a public awareness campaign and with sustained enforcement.

The WHO highlighted the importance of helmet use in preventing road traffic deaths in $2018 .^{2}$ However, of the 167 countries with mandatory helmet laws for motorcyclists, only $36 \%$ of the world population have a national motorcycle law that applies to both drivers and passengers, applicable to all road and engine types, specifying that helmets should be fastened, and with prescribed standards for helmets. Enforcement of these laws is generally weak globally, with only 61 countries exhibiting good enforcement, shown by scores of eight or above, on a scale of 0 to $10 .^{2}$

The Philippines was only rated 6 out of 10 in the enforcement of the helmet-wearing law. It was noted that despite having a national motorcycle helmet law that applies to drivers and passengers, with a prescribed helmet standard, the Philippine law does not require helmet fastening and does not restrict children passengers on motorcycles. ${ }^{2}$ Under Republic Act 10666, otherwise known as the Children's Safety on Motorcycles Act of 2015, children are only prohibited from riding motorcycles in public roads where there is a heavy volume of vehicles, high density of fast-moving vehicles, or where there is a speed limit higher than $60 / \mathrm{kph}$. Furthermore, children who can comfortably reach their feet on a standard foot peg of a motorcycle and whose arms can reach and grasp the driver's waist are allowed to ride a motorcycle. ${ }^{23}$

In addition, among those with information, almost all motorcycle crash patients had a history of alcohol intake. With this, the WHO (2018) rated the enforcement of the country's national drink-driving law with 4 , on the scale of 10 ; this is because the Philippines only met two out of the three best practices criteria in the drink-driving laws: the presence of a national drink-driving law and the blood alcohol component (BAC) limit not exceeding $0.05 \mathrm{~g} / \mathrm{dL}^{2}$ This law is Republic Act No. 10586, also known as the Anti-Drunk and Drugged Driving Act of 2013, which gives law enforcement officers the power to conduct a field sobriety test should they believe that a person was driving under the influence of alcohol. ${ }^{24}$ If the driver failed the sobriety test, the officer must implement a mandatory driver's blood alcohol concentration level using a breath analyzer or a similar measuring instrument. ${ }^{24}$ This, however, does not meet the WHO's recommended $0.02 \mathrm{~g} / \mathrm{dL}$ $\mathrm{BAC}$ limit for young and novice drivers; the same limit is used for both the general population and children. ${ }^{2}$

After motorcycles, road crashes involving bicycles, pedicabs, and motorcycles with sidecars ranked secondhighest patients in Metro Manila admitted in PGH.

More than half of road traffic deaths globally are among the vulnerable, including cyclists, motorcyclists, and pedestrians, neglected in many countries' roads traffic system design. In South-East Asia and the Western Pacific region, most deaths were among two- (43\%) and three-wheelers (36\%). ${ }^{2}$ According to Useche et al. (2019), self-reported risky behaviors of cyclists mediated the relationship between individual factors and crash rates among cyclists (p.105). ${ }^{9}$ Risky behavior fully mediated the association between knowledge of traffic rules, risk perception, and suffering from a traffic crash in five years. It also partially mediated the association between cycling intensity and traffic crashes. ${ }^{9}$

In comparison, based on the MMARAS data, trucks ranked the third vehicle type with the most road crash cases from 2014 to $2016 .^{7}$ Driving trucks for commercial activities are among the most hazardous driving occupations. In the meta-analysis by $\mathrm{Lu}$ in 2017 , most bus and truck drivers, from 2010 to 2015, worked more than 12 hours a day. ${ }^{25}$ Human error, including drunk driving, beating the red light, and sleepiness, was the top cause of road crash incidents among this group of drivers. ${ }^{25}$ However, in the study, the number of road crashes involving trucks was not significant.

\section{Road User Types}

Nearly half of the Metro Manila Road crash patients were drivers, making up the most significant road user types. They were followed by pedestrians who made up almost a third, and passengers comprised the smallest group of those 
admitted. In the MMARAS reports, it was seen that in terms of road crash injuries, it was also the drivers who consistently had the most significant number of injuries from 2012 to 2017 (Appendix J). ${ }^{7}$ There may be different factors affecting the injury severity of drivers depending on the nature of the crash and the environment where it happened. In New Mexico, data from 2010 to 2011 showed some common and other factors determining the driver injury severity in rural and urban crashes. The common factors included female sex drivers, senior citizens, alcohol impairment, and involvement in overturn or fixed-object crashes. As for the unique characteristics of rural crashes, these included the raining condition and no passing zone. For urban roadway crashes, factors included curved or multi-lane roadways and drug impairment of drivers. ${ }^{26}$ On the other hand, among rural single-vehicle crashes under rain conditions in four South Central states from 2012 to 2014, factors significantly associated with increased driver injury severity included being a male driver, curved road, on grade roads, presence of signal control, multiple lanes, pick-up vehicle type, driving straight, driving drug/alcohol-impaired, and driving with the seat belt that is not used. On the other hand, wet road surface, male driver, semi vehicle type or semi-truck vehicle type, and young driver or drivers aged below 25 years old were found to reduce driver injury outcomes. ${ }^{27}$

However, although drivers were the most involved in road crashes in Metro Manila, the pedestrians had the most significant number of fatalities from 2013 to 2017 (Appendix J). ${ }^{7}$ Similar results were seen in this study where half (50\%) of all the patients who died were pedestrians, while the drivers only made up a quarter (25\%) of all the total deaths. According to Versoza and Miles (2016), pedestrians were considered the most vulnerable road users in less developed countries, with $70 \%$ of all traffic-related fatalities globally occurring in these countries and $65 \%$ of these involving pedestrians. ${ }^{28}$ It was also explained that in rapidly urbanized areas like the Philippines, pedestrians were faced with the same problems as those in developed countries, but with more pedestrians in the streets and an environment that was not planned for high volume and speed of motor vehicles. In these environments, it was noted that more groups relied on mass transit, increasing their exposure to the risk of a traffic crash as pedestrians. In addition, heavy vehicles and varying subgroups of pedestrians, patterns of traffic violations involving street users, and the absence of accessible and safe pedestrian infrastructure further increased the risk of pedestrians being involved in road crash incidents. ${ }^{28}$

In the study which utilized Spain's registry of road crashes from 1993 to 2013, it was seen that pedestrian fatality increased with the maximum speed limit on each road type, and it was also higher in wider roads, roads with shoulders, and places with worse light conditions. It was lower in intersections, traffic circles, and roads or streets with sidewalks. As to the pedestrian characteristics, those with increasing age, physical defects, and infarction had a higher risk of fatality. On the other hand, the driver's age was inversely related to the risk of pedestrian death. At the same time, male sex, visual defects, abnormal psychophysical circumstances, and commission of a speed infarction were associated with a higher risk of pedestrian fatality. ${ }^{29}$

Walking is an integral part of an individual's daily trip, especially those in developing cities. This is mainly and specifically observed in developing metropolises such as Manila, where there is limited access to a motorized car and formal and informal public transport options. However, the environment where pedestrians walk in Manila created an overall negative image of pedestrians in this urban environment, which discourages these road users from walking. Mateo-Babiano's (2015) survey revealed that pedestrians in Quiapo, Manila, considered evening lighting, on-grade crossing at traffic signals, and police stand as their top protection needs; evening lighting, police stand, and transport stops are their top needs for ease. ${ }^{30}$

\section{Risky Driving Behaviors}

Patient data on the history of alcohol intake and drug intake were lacking in the database used in the study. Despite this, several patients were positive of history of alcohol intake. In addition, there was minimal information on the patients' history of falling asleep while driving. Moradi et al. (2018) discussed that while drowsy driving increased road crashes, it was difficult to determine the level of sleep-related road crashes. There was also no simple and reliable method for police officers to determine if the drivers involved in the crashes were suffering from fatigue or sleepiness and the level of their fatigue or sleepiness. ${ }^{31}$

\section{Hospital Management}

Almost all road crash patients in Metro Manila admitted to PGH were charity patients with urgent or emergency cases. The majority of these patients were admitted under the trauma service. Many were also managed under the plastic surgery service and the emergency department. In the study by Polinder et al. (2014), road traffic injury treated in the emergency department accounted for a large proportion of disability-adjusted life years lost. ${ }^{32}$ Most of the patients were co-managed under the Plastic Surgery service, followed by the Trauma and Urology service.

\section{Road Crash Injuries}

Road crash patients obtained injuries ranging from minor cuts and bruises that can be treated with basic medical care immediately to severe injuries requiring intensive or longitudinal care, which can last for several months involve multiple procedures. Some severe injuries can even lead to permanent disabilities. ${ }^{33}$

In this study, more than half of the patients had injuries in their external body region. These included lacerations, contusions, abrasions, and most burns (NSW Institute of Trauma and Injury Management, ND).$^{34}$ The findings were 
similar to a retrospective study in Nigeria (2009 - 2014). Common injury patterns included injuries to the extremities, specifically, mangled lower extremity, bilateral long bone lower limb fractures, and pelvic injuries. On the contrary, this study showed that blunt injuries to the chest and abdomen and cranial fossae fractures were not common in the Metro Manila study (Babalola et al., 2015, p.S21). ${ }^{35}$ In another study, more than one-third of the patients had injuries in their extremities, and a quarter of the patients had injuries in their facial region. Among victims of a lead vehicle stop crash, patients most frequently acquired injuries in the thorax, lower and upper extremities. Thorax injuries were usually brought about by steering wheel contact, while a knee bolster accounted for most lower extremity injuries. ${ }^{36}$

The majority of the patients from the road crash incidents obtained multiple injuries. Among those with final diagnoses after the road crash, almost half brought injuries to two body regions, followed by injuries to a single body region, and patients who suffered from injuries to three body regions. $\mathrm{Yu}$ et al. (2017) suggested that the outcomes of multiple road traffic injuries were similar to those of single road traffic injuries, but their influencing factors vary. ${ }^{37}$ However, those with multiple injuries were more likely to have severe injuries and be at a higher risk of death. Among patients with multiple injuries, those with more body regions injured were more likely to incur more severe injury conditions. ${ }^{37}$

Among the patients who had injuries to only one body region, those with external injuries ranked the highest, followed by patients with injuries to the extremities and then injuries to the abdominal region. On the other hand, patients with injuries to the head and neck region, facial region, and external region were the highest among those with three body regions injured. The mean number of body regions injured among all patients was 1.75 with a standard deviation of \pm 0.909 . A study in Shanghai suggested that patients who sustained a single road traffic injury in the head, thorax, and pelvis were more likely to go into a coma and developed complications. ${ }^{37}$ The combinations of body parts injured were also investigated. It was seen that patients with injuries to the extremities and external region ranked the highest among those with two body regions injured. Another study claimed that motorcyclists and pedestrians involved in collisions with reversing cars were at the most significant risk for severe injuries involving lower extremities and upper extremities. ${ }^{38}$ While this study did not focus on this type of collision, most of the patients involved in our research were motorcyclists and pedestrians.

\section{Physical Examination}

The patients mostly presented with vital signs (blood pressure, heart rate, respiratory rate) within normal ranges. Patients with head and neck injuries also mostly presented with a GCS of 15 interpreted as having no brain injury.

The GCS is a reliable structured method to assess the level of consciousness based on the patient's motor, verbal, and eye responses. This allows for the comparison of changes in patient status through time which can influence the treatment plan for the patient (Reith et al., 2016, pp.3-4). ${ }^{39}$ A depressed GCS can also be a measure that predicts the mortality of patients. However, this is more effective among patients with traumatic brain injury than those without. A depressed GCS may be brought about by reversible intoxication on alcohol or drugs (Osler et al., 2016, pp.1879-1878). ${ }^{40}$ GCS scores below eight are associated with poor outcomes among road crash patients with traumatic head injuries (Chelly et al., 2017, p.1), road crash patients who sustained injuries to the head, neck, chest, abdomen, internal organs, spine, and other injuries were seen to have lower GCS scores. ${ }^{41}$ In addition, injuries to the head, neck, chest, abdominal and pelvic regions can lead to statistically significantly lower mean GCS. ${ }^{42}$

\section{Road Crash Deaths}

Road traffic death rates declined from 135 deaths in every 100,000 vehicles in 2000 to approximately 64 deaths in every 100,000 vehicles in the year 2016. Despite this implied road safety progress globally, this progress was not uniform across regions and income levels. This is because the risk of dying due to a road crash is still strongly associated with a countries' income levels. The low- and middle-income countries experienced a disproportionately high burden of road traffic deaths with their population size and motor vehicles in circulation. ${ }^{2}$ These road crashes did not only yield human consequences. Still, they can also severely burden a country's economy, bringing about high costs, including medical expenses, production losses, human losses, property damage, and settlement costs. ${ }^{3}$

Moreover, road crash injuries were the only and most significant cause of mortality among young people from 15 to 29 years old, significantly affecting the working population. Therefore, reducing these injuries can positively affect national income growth. In the Philippines, reducing the road crash mortality and morbidity rates by half and sustaining it for 24 years can yield an additional income. ${ }^{4}$

Low- and middle-income countries lack almost everything needed to combat road crash injuries and deaths. These include the lack of leadership, lack of political priority, lack of funding, and lack of expertise. ${ }^{3}$ In the Philippines, there is no available and consistent health and non-health data for road traffic fatality at the national level from 1985 to 2013. Data observed had been present for less than five years. ${ }^{5}$

The Metro Manila Development Authority (MMDA) is the government agency in charge of transport and traffic management within the National Capital Region. ${ }^{6}$ Through the Metro Manila Accident Reporting and Analysis System (MMARAS), the MMDA compiles and maintains an ongoing database of road crashes in the National Capital Region. From 2007 to 2017, the total number of road crashes in the region were almost constantly increasing. ${ }^{7}$ This includes a constant increase in the yearly number of fatalities and injuries from road crashes in Metro Manila. 
Atiksawedparit et al. (2019) conducted a multicentercross-sectional study among road crash patients. It was seen that demographic data, crash characteristics, emergency medical services operation domain, mechanism of injury, physiological data, environmental domain, and risk behavior domain were predictors of road crash deaths. These included blunt injuries and GCS. ${ }^{43}$

More than half of the patients who died in this study sustained injuries in the head and neck region. These included injuries to the cervical spine, the skull, and the brain. Almost half of those who died also had injuries to their external area, which encompassed lacerations, contusions, abrasions, and most kinds of burns. Nearly all patients who died were diagnosed with multiple injuries. In a study in England from 2007 to 2012, head injury was the leading cause of death in cyclists. Multiple injuries were prevalent among pedestrians and drivers. ${ }^{44}$

Almost all patients (90.3\%) attained a recovered or improved status upon discharge in our PGH study. However, $4.7 \%$ had unchanged status from admission to discharge, while $3.5 \%$ died in the hospital.

A retrospective study of consecutive autopsy data of road crash victims found that head and thoracic injuries were the leading cause of death among blunt trauma nonsurvivors. ${ }^{45}$ Similarly, in the study, road crash victims who obtained injuries to their head and neck regions were five times more likely to die and six times more likely to have unchanged status. This was consistent with a forensic study in Tokyo Women's Medical University, where skull fractures and deaths from multiple head and trunk injuries were seen to be significantly higher in road crash patients. According to this study, most head injuries were caused by blunt force trauma, usually seen in road crashes. In addition, patients who underwent a transmission of high kinetic energy to the body, such as what happens in road crashes, are usually characterized by head and trunk injuries. ${ }^{46}$ This is further supported by a study in Malawi from 2011 to 2015 among adult trauma patients where it was seen that head and spine injuries most likely occurred on the road. These kinds of injuries usually need to be treated in the intensive care unit and high dependency units and were found to have caused the highest mortality among the patients. ${ }^{47}$

Another related finding was that patient with GCS scores of 8 and below were eight times more likely to die and eight times more likely to have an unchanged patient status than patients who did not have severe brain injuries. This is supported in a study where patients with GCS scores of 8 or less have a $40 \%$ risk of dying from traumatic brain injury. ${ }^{47}$ The patient's GCS score upon admission is correlated with their prognosis with trauma. ${ }^{48}$ In our study in PGH, it was also seen that patients who had GCS of 8 and below or those who had severe brain injuries were eight times more likely to die and six times more likely to have an unchanged patient outcome.

\section{CONCLUSION}

This study looked into the epidemiology of road crash cases admitted in the Surgery Department of the PGH. Road crash injuries and deaths remain to be a growing concern among the citizens of Metro Manila. It is hoped that the results of this study shall provide policymakers an objective and data-driven perspective on road crashes.

It is recommended that regulations affecting vulnerable road users, including the Motorcycle Act of 2009, be implemented more effectively.

Motorcycle and bike lanes must be provided to ensure that cyclists will not contact bigger motor vehicles, thus reducing the risk of crashes involving this vulnerable population.

It is recommended that a more comprehensive road safety recording system be implemented in PGH and all hospitals in Metro Manila and the rest of the country.

While the current recording system provides extensive data on road crashes within the region, it is recommended that road crash injuries and deaths data from all the hospitals in Metro Manila be explored to provide a complete picture of the road safety status in the region.

Moreover, it is recommended that a national guideline be created and implemented for a more systematic and comprehensive national road safety monitoring system involving government units and trauma hospitals, instead of our current fragmented surveillance system, which fails to give health researchers and policymakers analyzable data on road safety in the country.

\section{Statement of Authorship}

All authors contributed in the conceptualization of work, acquisition and analysis of data, drafting and revising, and final approval of the version to be published.

\section{Author Disclosure}

All authors declared no conflicts of interest.

\section{Funding Source}

This study was funded by the Emerging Interdisciplinary Research (EIDR) of the University of the Philippines System.

\section{REFERENCES}

1. World Health Organization. Global launch: decade of action for road safety 2011-2020 [Internet]. World Health Organization; Geneva: World Health Organization; 2011 [cited 2019 Apr]. Available from: https://www.who.int/roadsafety/publications/global_launch.pdf.

2. World Health Organization. Global status report on road safety 2018: summary [Internet]. Geneva: World Health Organization; 2018 [cited 2019 Apr]. Available from: https://www.who.int/ publications/i/item/9789241565684.

3. Wegman F. The Future of Road Safety: A worldwide perspective. IATSS Res. 2017;40(2): 66-71.

4. Bose D, Segui-Gomez M, Crandall JR. Vulnerability of Female Drivers Involved in Motor Vehicle Crashes: An Analysis of US Population at Risk. Am J Public Health. 2011 Dec;101(12): 2368-73. doi: 10.2105/AJPH.2011.300275. 
5. Huang H, Yin Q, Schwebel DC, Ning P, Hu G. Availability and Consistency of Health and Non-health Data for Road Traffic Fatality: Analysis of Data from 195 Countries, 1985-2013. Accid Anal Prev. 2017 Nov; 108:220-6. DOI: 10.1016/j.aap.2017.08.033.

6. Metropolitan Manila Development Authority. Transparent Governance [Internet]. ND. [cited 2019 Apr] Available from http://www.mmda.gov. $\mathrm{ph} / 10$-transparency/6-mmda-s-scope-of-services-its-functions-andpowers.html.

7. Metropolitan Manila Development Authority. Road Crash Statistics in Metro Manila (2007-2017) [Internet]. 2018 [cited 2019 Mar] Available from https://www.foi.gov.ph/requests/aglzfmVmb2ktcGhyHgsSB0NvbnRlbnQiEU1NREEtNjYxMTU2NTgwOTgzDA.

8. Alfalahi E, Assabri A, Khader Y. Pattern of Road Traffic Injuries in Yemen: A Hospital-based Study. Pan Afr Med J. 2018 Mar 5; 29:145. doi: 10.11604/pamj.2018.29.145.12974.

9. Useche SA, Alonso F, Montoro L, Esteban C. Explaining Selfreported Traffic Crashes of Cyclists: An Empirical Study based on Age and Road Risky Behaviors. Saf Sci. 2019 Mar; 113:105-114. doi: 10.1016/j.ssci.2018.11.021.

10. Regev S, Rolison JJ, Moutari S. Crash Risk by Driver Age, Gender, and Time of Day Using a New Exposure Methodology. J Safety Res. 2018 Sep;66:131-140. doi.org/10.1016/j.jsr.2018.07.002.

11. Metropolitan Manila Development Authority. MMARAS Annual Report 2012 [Internet]. 2012 [cited 2019 Mar]. Available from https:// www.foi.gov.ph/requests/aglzfmVmb2ktcGhyHgsSB0NvbnRlbnQiEU1NREEtMDQwMTc1NjY2NjMzDA.

12. Metropolitan Manila Development Authority. MMARAS Annual Report 2013 [Internet]. 2013 [cited 2019 Mar]. Available from https:// www.foi.gov.ph/requests/aglzfmVmb2ktcGhyHgsSB0NvbnRlbnQiEU1NREEtMDQwMTc1NjY2NjMzDA.

13. Metropolitan Manila Development Authority. MMARAS Annual Report 2014 [Internet]. 2014 [ cited 2019 Mar]. Available from https:// www.foi.gov.ph/requests/aglzfmVmb2ktcGhyHgsSB0NvbnRlbnQiEU1NREEtMDQwMTc1NjY2NjMzDA.

14. Metropolitan Manila Development Authority. MMARAS Annual Report 2015 [Internet]. 2015 [cited 2019 Mar]. Available from https:// www.foi.gov.ph/requests/aglzfmVmb2ktcGhyHgsSB0NvbnRlbnQiEU1NREEtMDQwMTc1NjY2NjMzDA.

15. Metropolitan Manila Development Authority. MMARAS Annual Report 2016 [Internet]. 2016 [cited 2019 Mar]. Available from https:// www.foi.gov.ph/requests/aglzfmVmb2ktcGhyHgsSB0NvbnRlbnQiEU1NREEtMDQwMTc1NjY2NjMzDA.

16. Lu SFD. 530 Road Crashes in Metro Manila: Overview of Road Safety [abstract]. Inj Prev. 2016; 22 Suppl 2:A191.

17. Anarkooli AJ, Hosseinlou MH. Analysis of the Injury Severity of Crashes by Considering Different Lighting Conditions on Two-lane Rural Roads. J Safety Res. 2016 Feb; 56:57-65.

18. Ali MS, Sheeraz K. Time Dynamic Characteristics for Road Crashes in Developing Countries. Procedia Eng. 2014; 77:79-86.

19. Bassani M, Catani L, Cirillo C, Mutani G. Night-time and Daytime Operating Speed Distribution in Urban Arterials. Transp Res Part F: Traffic Psychol Behaviour. 2016 Oct; 42(Pt 1):56-69.

20. Gilandeh SS, Hosseinlou MH, Anarkooli AJ. Examining Bus Driver Behavior as a Function of Roadway Features Under Daytime and Nighttime Lighting Conditions: Driving Simulator Study. Saf Sci. 2018 Dec; 110:142-51.

21. Bella F, Calvi A, D'Amico F. Analysis of Driver Speeds Under Night Driving Conditions Using Driving Simulator. J Safety Res. 2014 Jun; 49:45-52.

22. Consunji R, Jumangit III A, Larona A, Ameratunga S. Motorcyclerelated Trauma in the Philippines Resulting in Hospital Admission: The Epidemiology of Cases at the Philippine General Hospital. Acta Med Philipp. 2013 Sep; 47(3):11-4.

23. Children's Safety on Motorcycles Act of 2015, R. A. No. 10666 (July 27, 2015)

24. Anti-Drunk and Drugged Driving Act of 2013, R. A. No. 10586 (May 27, 2013).

25. Lu SF.0010 Epidemiology of Road Crash and Accident Fatalities among Bus and Truck Drivers: Vulnerable Occupational Group. Occup Environ Med. 2017 Aug; 74 Suppl 1:A2.

26. Wu Q, Zhang G, Zhu X, Liu XC, Tarefder R. Analysis of Driver Injury Severity in Single-vehicle Crashes on Rural and Urban Roadways. Accid Anal Prev. 2016 Sep; 94:35-45.
27. Li Z, Ci Y, Chen C, Zhang G, Wu Q, Qian ZS, et al. Investigation of Driver Injury Severities in Rural Single-vehicle Crashes Under Rain Conditions Using Mixed Logit and Latent Class Models. Accid Anal Prev. 2019 Mar; 124:219-29.

28. Verzosa N, Miles R. Severity of Road Crashes Involving Pedestrians in Metro Manila, Philippines. Accid Anal Prev. 2016 Sep; 94:216-26.

29. Martínez-Ruiz V, Valenzuela-Martínez M, Lardelli-Claret P, MolinaSoberanes D, Moreno-Roldán E, Jiménez-Mejías E. Factors Related to the Risk of Pedestrian Fatality after a Crash in Spain, 1993-2013. J Transp Health. 2019 Mar;12:279-89.

30. Mateo-Babiano, I. Pedestrian's Needs Matter: Examining Manila's Walking Environment. Transp Policy. 2016 Jan; 45:107-15.

31. Moradi A, Nazari SSH, Rahmani K. Sleepiness and the Risk of Road Traffic Accidents: A Systematic Review and Meta-analysis of Previous Studies. Transp Res Part F: Traffic Psychol Behav. 2019 Aug; 65:620-9.

32. Polinder S, Haagsma J, Bos N, Panneman M, Wolt KK, Brugmans M, et al. Burden of Road Traffic Injuries: Disability-adjusted Life Years in Relation to Hospitalization and the Maximum Abbreviated Injury Scale. Accid Anal Prev. 2015 Jul; 80:193-200.

33. Zafar SN, Canner JK, Nagarajan N, Kushner AL, Gupta S, Tran TM, et al. Road Traffic Injuries: Cross-sectional Cluster-randomized Countrywide Population Data from 4 Low-income Countries. Int J Surg. 2018 Apr; 52:237-42.

34. NSW Institute of Trauma and Injury Management. Injury Severity Score [Internet]. 2008 [cited 2019 Mar]. Available from https://aci.health.nsw. gov.au/get-involved/institute-of-trauma-and-injury-management/data/ injury-scoring/injury_severity_score.

35. Babalola OR, Oluwadiya K, Vrgoč G, Akpati U, Sindik J, Čoklo M, et al. Pattern of Emergency Room Mortality among Road Traffic Crash Victims. Injury. 2015 Nov; 46 Suppl 6:S21-S3.

36. Eichaker LR. Injury Mechanisms and Outcomes in Lead Vehicle Stopped, Near Side, and Lane Change-related Impacts: Implications for Autonomous Vehicle Behavior Design [dissertation]. Colombus $(\mathrm{OH})$ The Ohio State University; 2017.

37. Yu W, Chen H, Lv Y, Deng Q, Kang P, Zhang L. Comparison of Influencing Factors on Outcomes of Single and Multiple Road Traffic Injuries: A Regional Study in Shanghai, China (2011-2014). PloS One. 2017 May 11; 12(5):e0176907. PubMed PMID: 28493893.

38. Decker S, Otte D, Cruz DL, Müller CW, Omar M, Krettek C, et al. Injury Severity of Pedestrians, Bicyclists and Motorcyclists Resulting from Crashes with Reversing Cars. Accid Anal Prev. 2016 Sep; 94: 46-51.

39. Reith FC, Lingsma HF, Gabbe BJ, Lecky FE, Roberts I, Maas AI. Differential Effects of the Glasgow Coma Scale Score and its Components: An analysis of 54,069 Patients with Traumatic Brain Injury. Injury. 2017 Sept; 48(9):1932-43.

40. Osler T, Cook A, Glance LG, Lecky F, Bouamra O, Garrett M, et al. The Differential Mortality of Glasgow Coma Score in Patients With and Without Head Injury. Injury. 2016 Sept; 47(9):1879-85.

41. Chelly H, Bahloul M, Ammar R, Dhouib A, Mahfoudh KB, Boudawara MZ, et al. Clinical Characteristics and Prognosis of Traumatic Head Injury following Road Traffic Accidents Admitted in ICU "Analysis of 694 cases”. Eur J Trauma Emerg Surg. 2019 Apr; 45(2):245-53.

42. Alqarni A, Alanazi R, Morgan A, Alharbi A, Aljuaid F, Aldawsari $\mathrm{A}$, et al. Injuries Type and Its Relation with Glasgow Coma Scale, Injury Severity Score and Blood Transfusion in Road Traffic Accident Victims. Med Perspekt. [Internet]. 2018 Jun [cited $2021 \mathrm{Mar}$;23(2): 148-59. Available from: http://journals.uran.ua/index.php/2307-0404/ article/view/133954.

43. Atiksawedparit P, Rattanasiri S, Sittichanbuncha Y, McEvoy M, Suriyawongpaisal P, Attia J, et al. Pre-hospital Prediction of Severe Injury in Road Traffic Injuries: A Multicenter Cross-sectional Study. Injury. 2019 Sep; 50(9):1499-506.

44. Martin A, Lloyd M, Sargent G, Feleke R, Mindell JS. Are Head Injuries to Cyclists an Important Cause of Death in Road Travel Fatalities? J Transp Health. 2018; 10:178-85.

45. Pfeifer R, Schick S, Holzmann C, Graw M, Teuben M, Pape HC. Analysis of Injury and Mortality Patterns in Deceased Patients with Road Traffic Injuries: An Autopsy Study. World J Surg. 2017 Dec; 41(12):3111-19.

46. Kibayashi K. Prevention of Head Trauma and Death in Patients with Head Injuries: A Forensic Autopsy Study. IATSS Res. 2019 Jul; 43(2):71-4.

47. Eaton J, Grudziak J, Hanif AB, Chisenga WC, Hadar E, Charles A. The Effect of Anatomic Location of Injury on Mortality Risk in a Resource-poor Setting. Injury. 2017 Jul; 48(7):1432-8. 